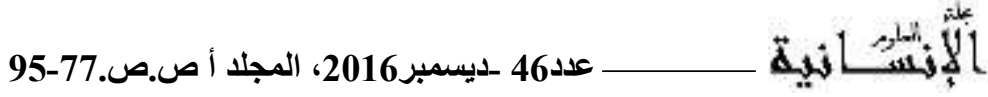

\section{النظام القانوني لاستعمال الملك العام المائي}

\author{
لوصيف نوال \\ كلية الحقوق \\ جامعة الإخوة منتوري قسنطينة
}

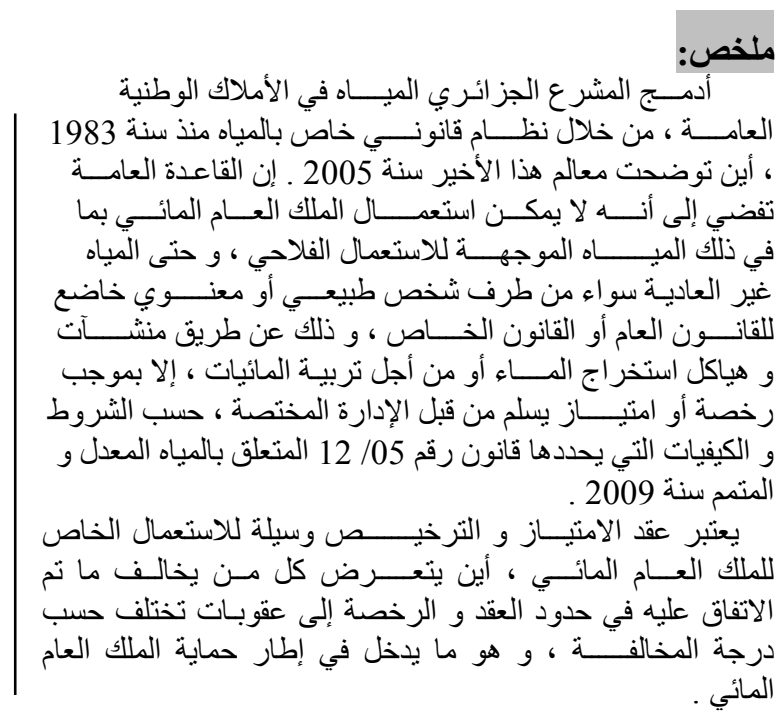

مقدّمة:

لقد اهتم المشـرع الجز ائري بـالأملاك

الوطنيـة و أدرج ضـمنها الملك العـــــــام

المـائي ، أيـن نطـرق إليـهـ بصـفة عامـة

محيلا هذا الموضـوع مـن خـلال قـانون

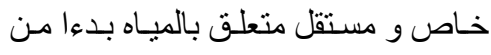

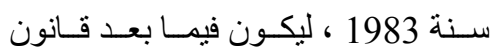

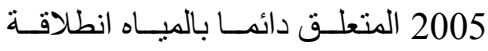

حقيقية و فعلية للتصور الثامل و الموسع

لقطاع الميـاه، كمـا ذهب إلى وضهـع عقد

الامتيـاز و حالات منح رخصة استعمال

الملك العام المائي في إطار قانوني محدد

من خلال نصوص قانون المياه المعدل و

المـتمم ســنة 2009 ـ تطــرق قانـــــون

الأمـلاك الوطنيـة إلــى إخضـاع تطبيـق

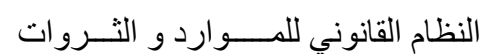

\section{Abstract :}

The integration of the Algerian legislator water in national public property, through the institution special water since 1983, where illustrate this mast landmarks in2005.

The general rule is conducive to that you can not use public property water. Including water not normal whether by natural person or legal entity under the common law or private law. Through by system and structure of water drawing or for aquaculture, expect under license or privilege delivered by the competent administration, according to the condition and modalities determined by law $\mathrm{N}^{\circ}$ 12/05related modified and complemented for 2009. It is the concession contract and the license means the private use of public domain water, where being both contrary to what has been agreed upon within the limits of the contract and the license to the penalties vary depending on the degree of the offense, which is part of the public property to protect water.

(C) جامعة الإخوة منتوري، قسنطينة، الجزائر 2016. 
الطبيعية و أنماط استغلالهـاو قو اعد تسيير ها ، كذلك أشغال التتقيــب و البحث و استصلاح الحقــول

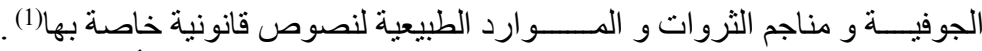
كما تطرق في نفس السياق و بصفة خاصة للحديث عن مكونات الأملاك العمومية الطبيعيــــة من

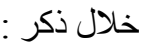

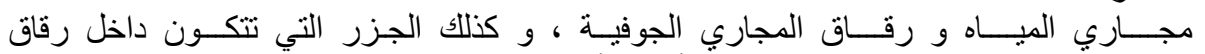

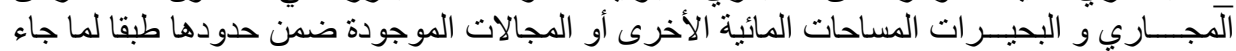
في قانون المياه(2) لم يغفل قانون المياه رقم 12/05 المتعلق بالمياه المعدل و المتمم(3) تحديد مكونات الأملاك العمومية

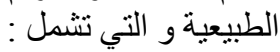

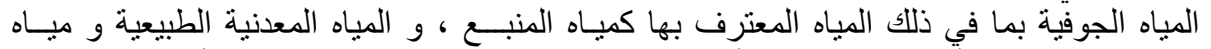

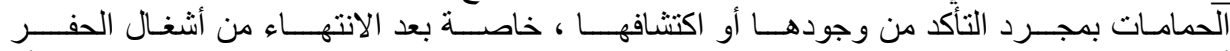

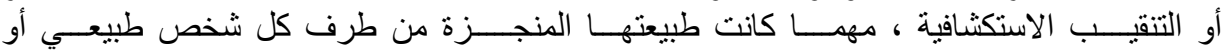

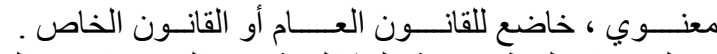

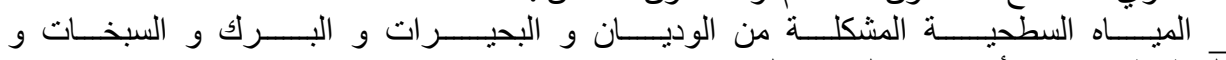

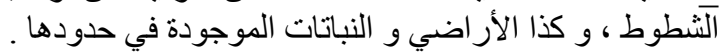

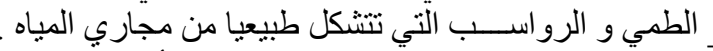

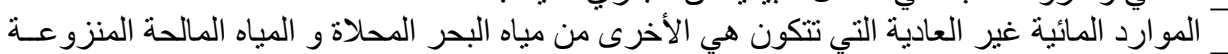

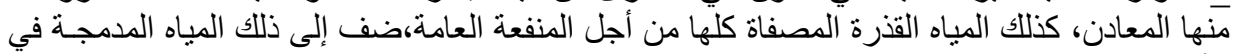

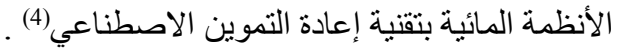

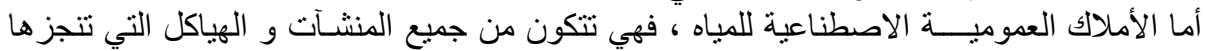

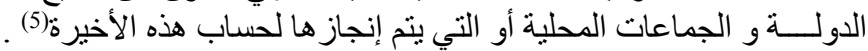

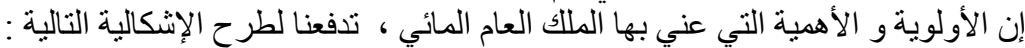

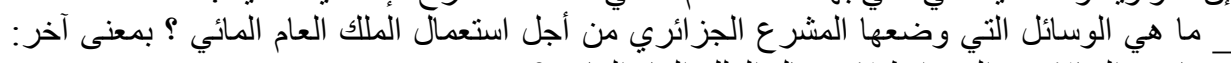

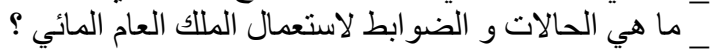

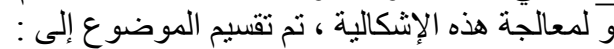

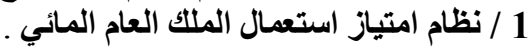

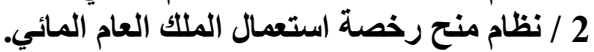

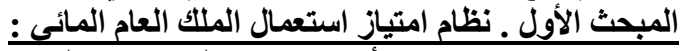

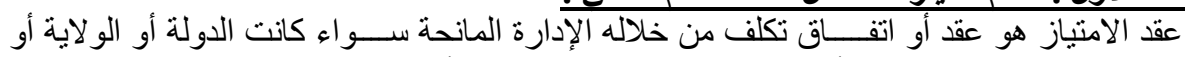

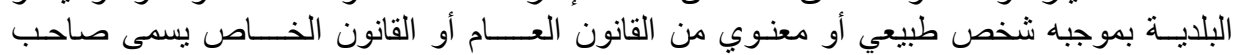

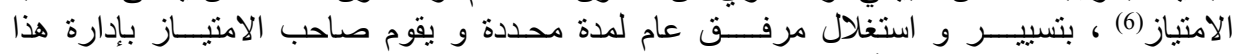

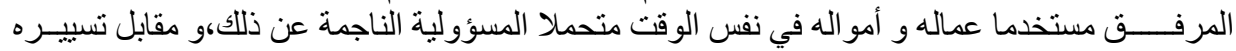

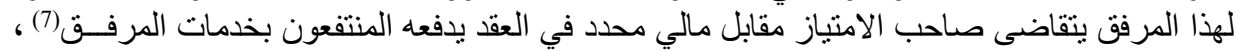


و تعتبر تلبية حاجات المرفق العام الدافع الحقيقي للاخول في العملية التعاقدية(8) ، و عليه يسلم امتياز

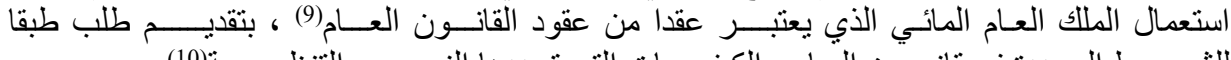

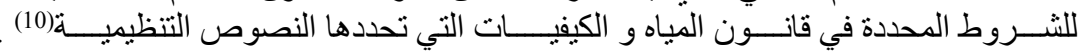

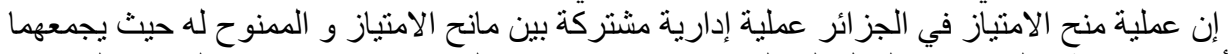

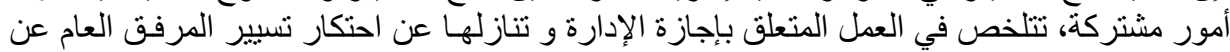

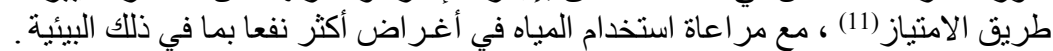

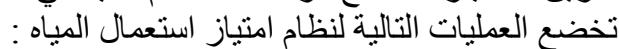

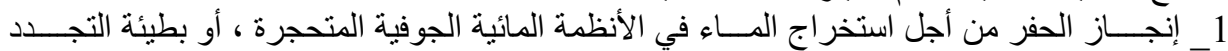

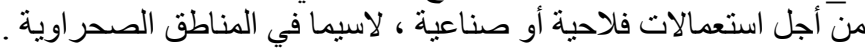

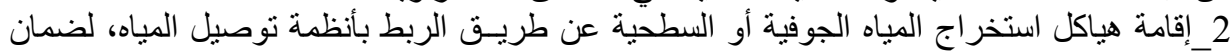
التموين المستقل للمناطق أو الوحدات الصناه الصناعية .

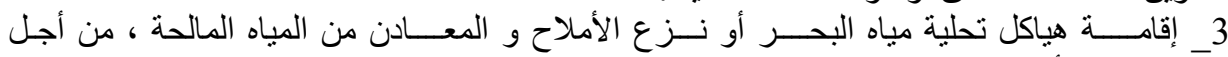

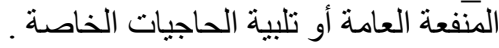

4 إنجـاز المنشآت الموجهة لاستعمال المياه القذرة المصفاة من أجل الاستعمالات الفلاحية الفردية،

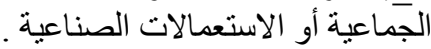

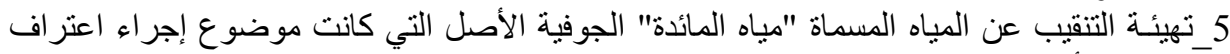

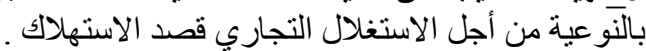

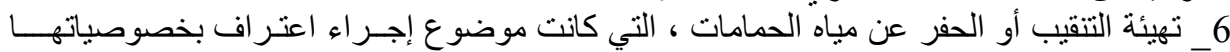

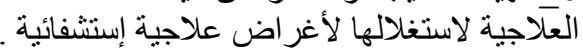

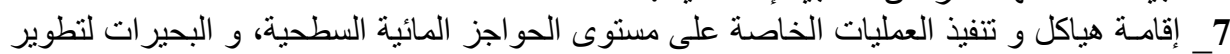

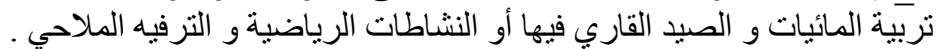

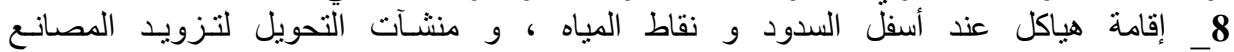

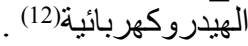

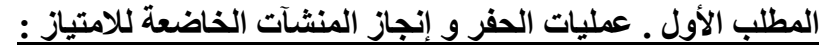

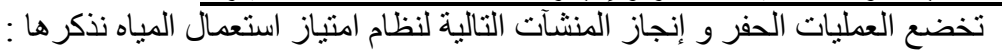

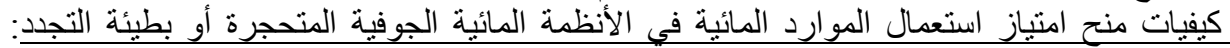

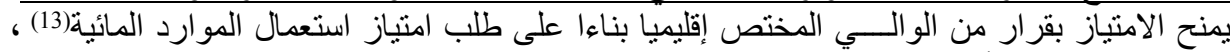

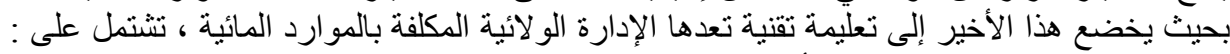

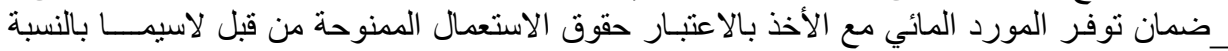

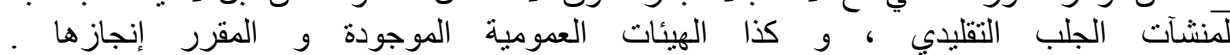

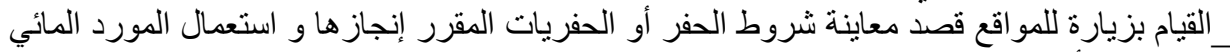

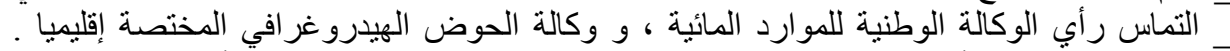

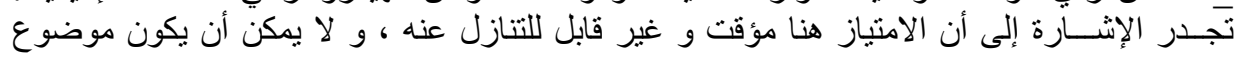


كر اء للغير و إلا وقع تحت طائلة البطلان(14) .

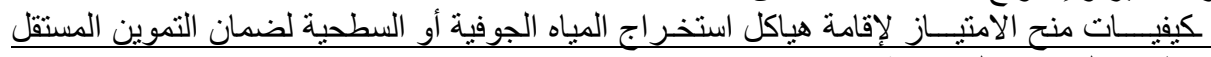

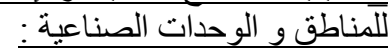

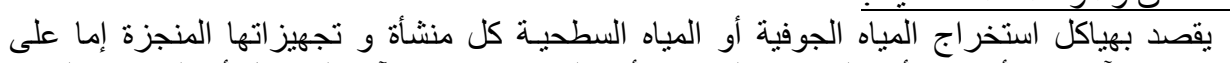

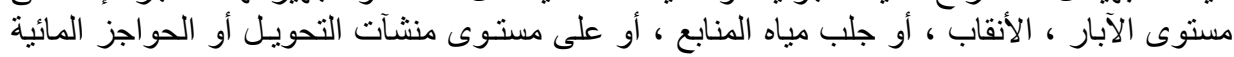

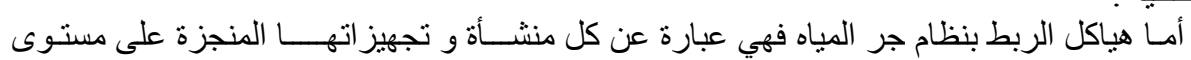

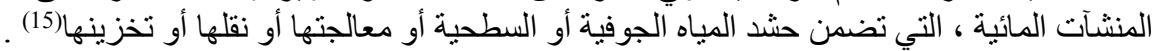

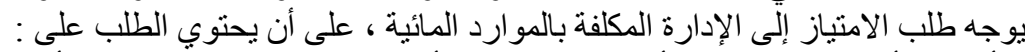

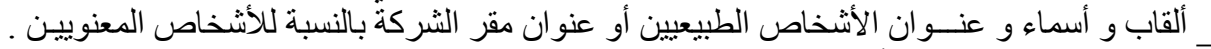

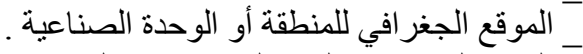

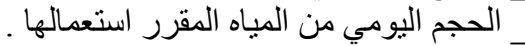

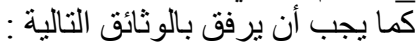

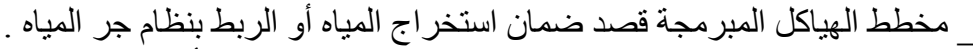

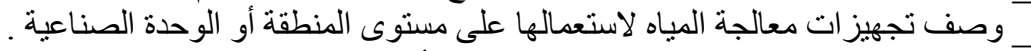

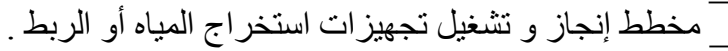

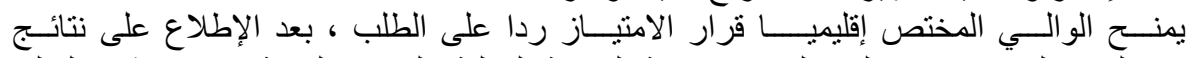

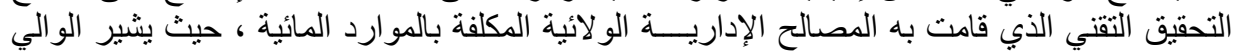

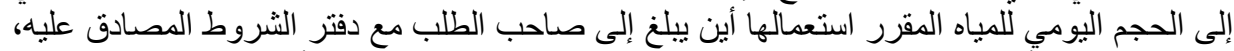

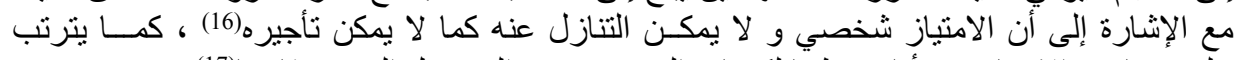

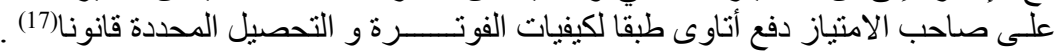

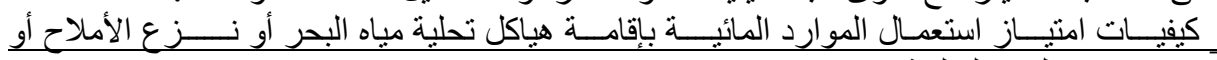

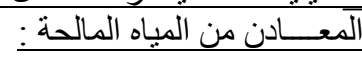

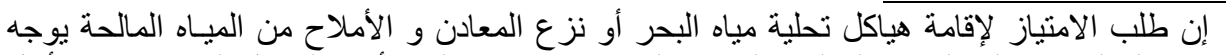

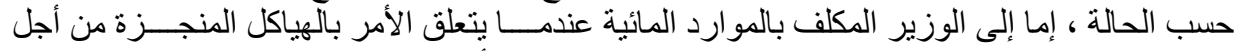

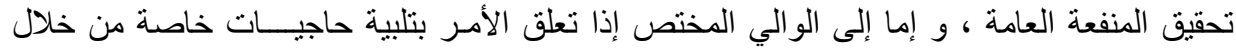

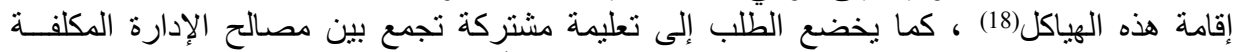

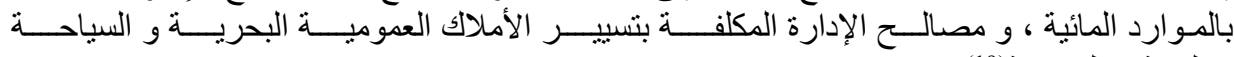

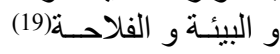
يتضمن هذا الطلب البيانات التالية :

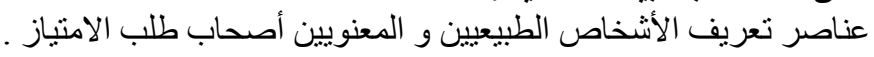

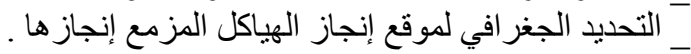
_ حجم المياه الواجب إنتاجها في اليوم . 
الاستعمال المرتقب للمياه المنتجة .

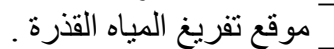

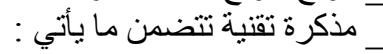

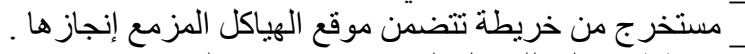

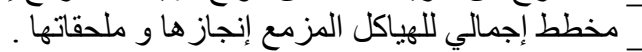

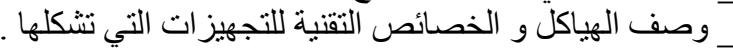

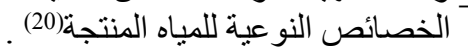

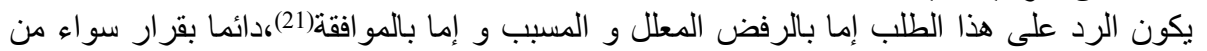

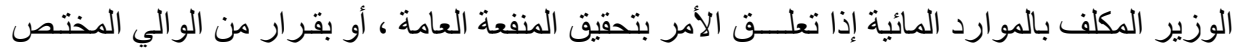

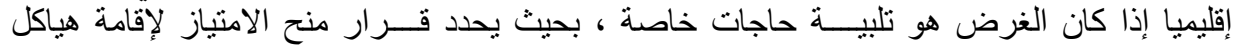

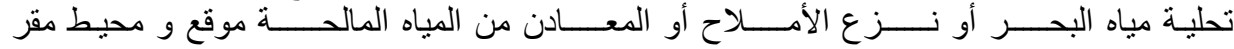

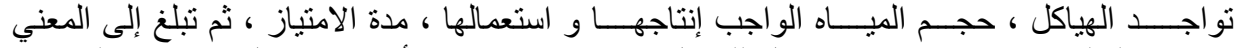

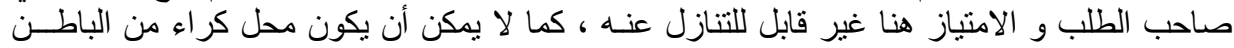

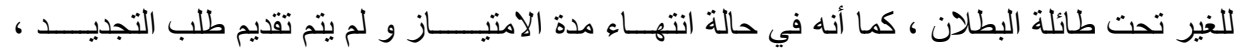

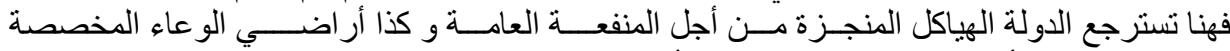

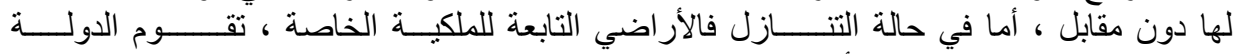

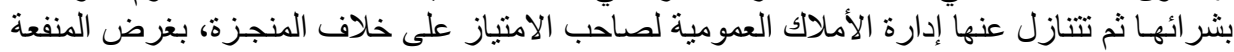

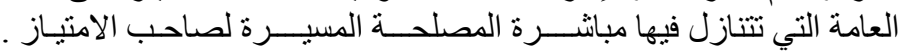

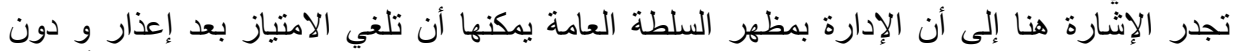

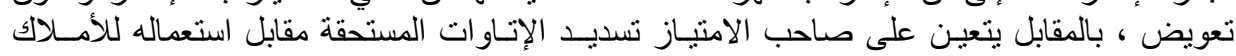

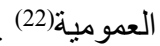

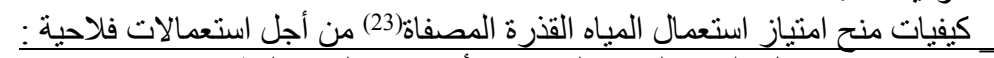

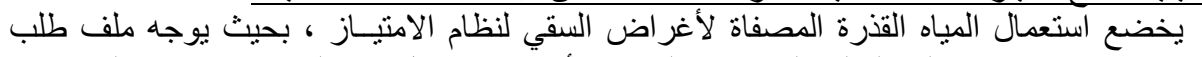

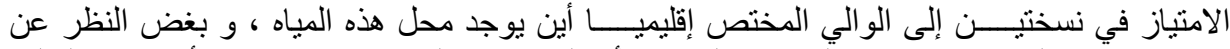

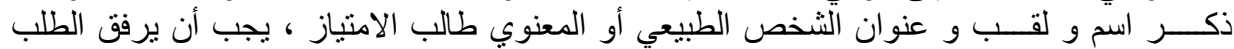

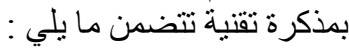
ـ وصف محطة أو حوض التصفية مصدر المباه القذرة المصفاة ، و كيفية المعالجة المستعطلة .

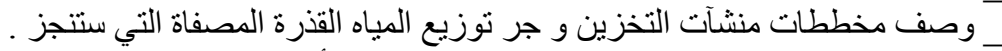

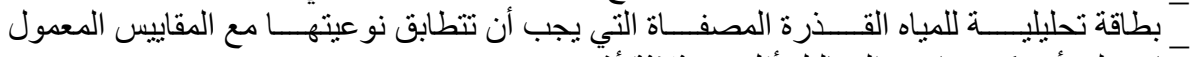

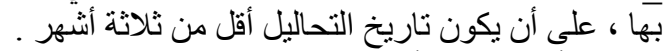

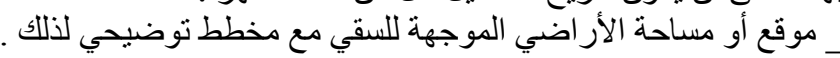

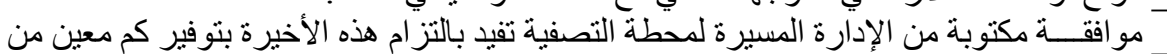

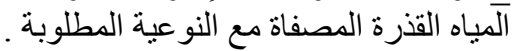


التز ام الفلاحين المستعملين للمياه القذرة المصفاة .

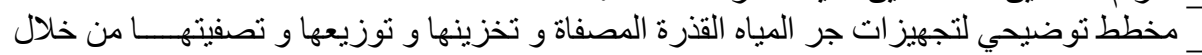

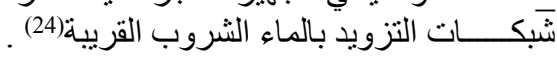

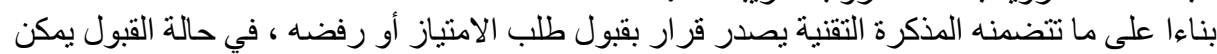

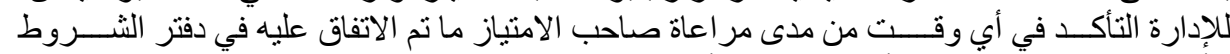

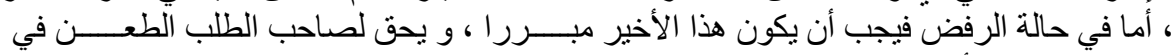

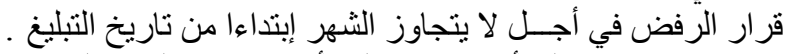

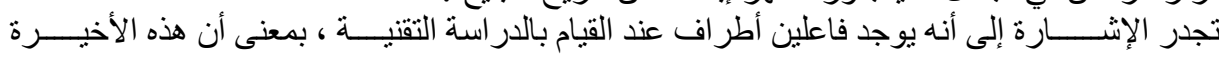

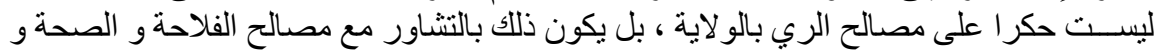
حماية البيئة(25). . حلئ.

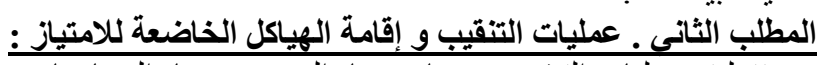

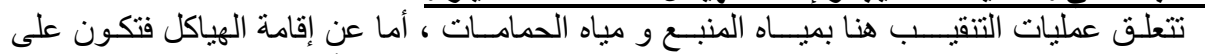

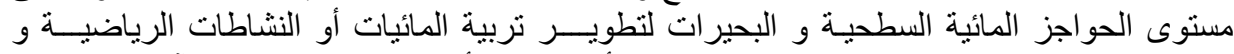

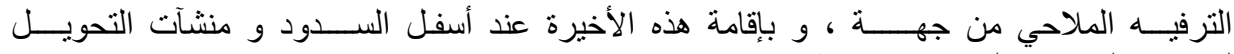

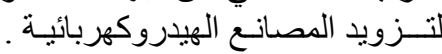

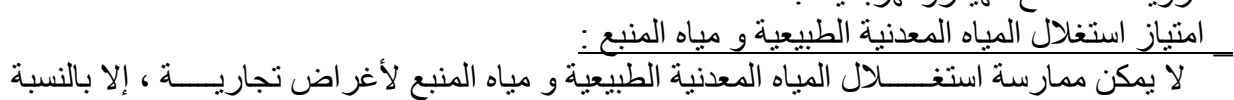

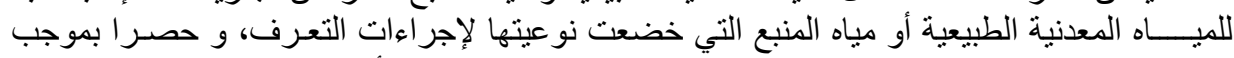

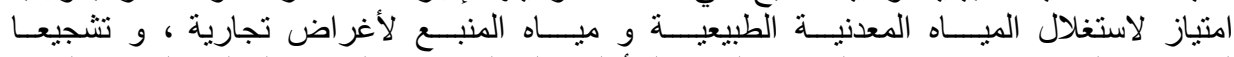

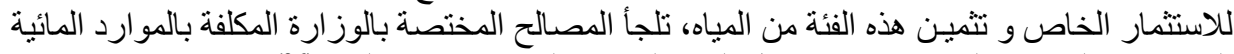

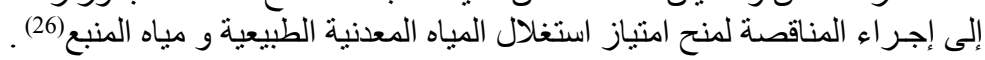

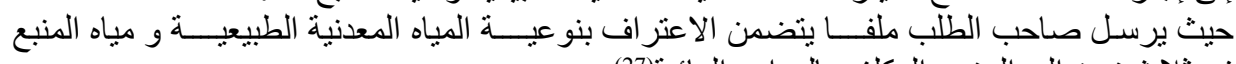

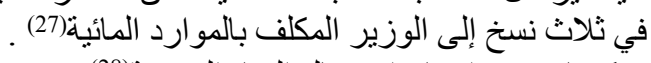

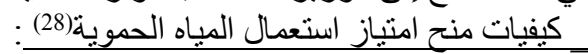

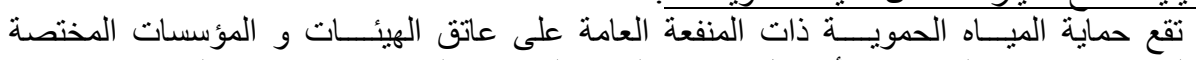

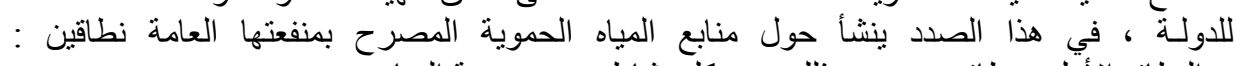

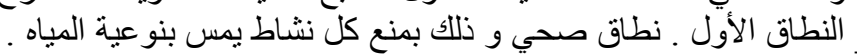

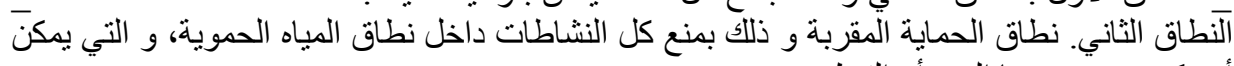

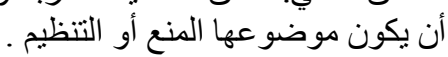

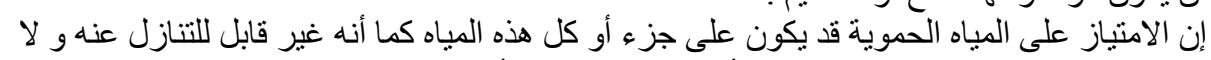

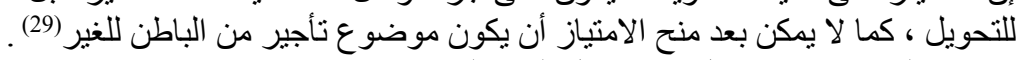

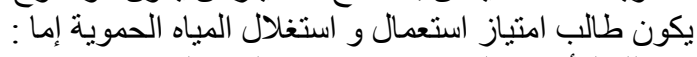

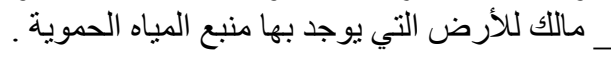


مالك لحق التمتع أو لسند تأجير مثبت بعقد توثيقي للاستعمال و استغلال المباه الحموية لمدة تساوي

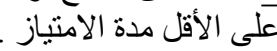

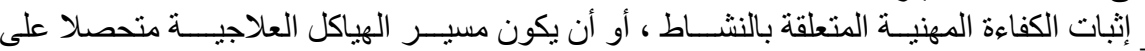

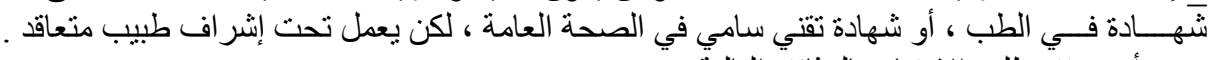
يجب أن يرفق طلب الامتياز بالوثائق التالية :

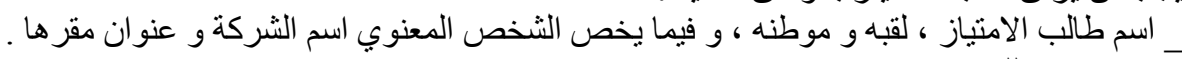

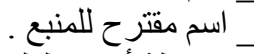

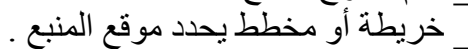

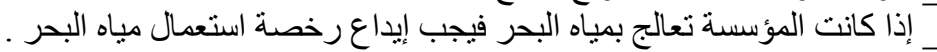

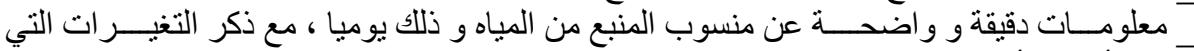

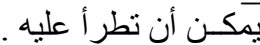
ـ موقع المنبع الحموي موضو عايه ع طلب الامتياز ، طبقا للبيانات الموجودة في الحصيلة .

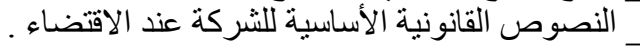

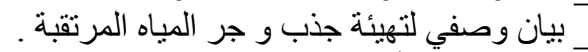

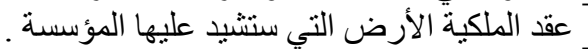

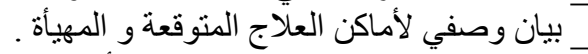

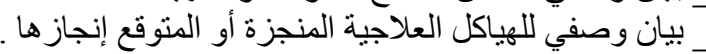

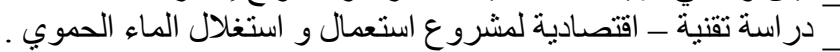

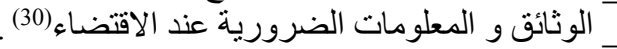

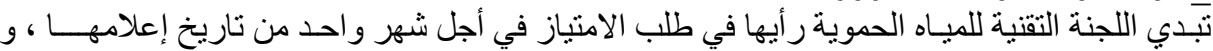

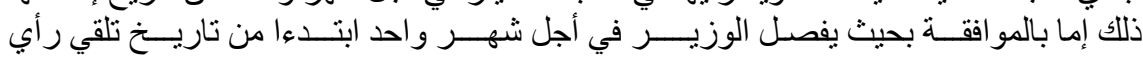

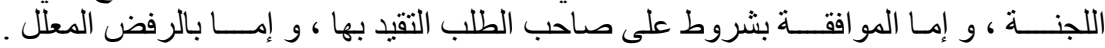

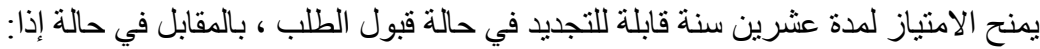

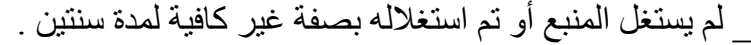

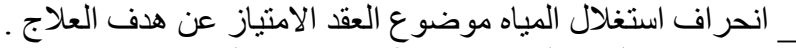

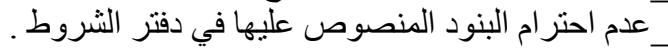

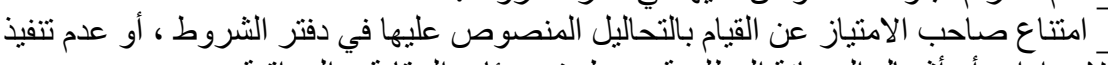

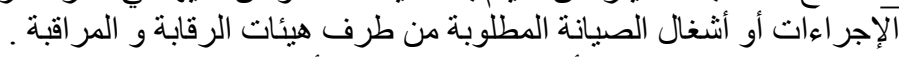

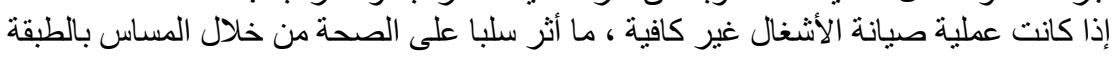

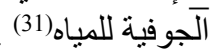

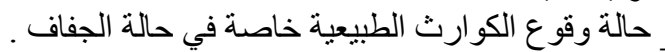

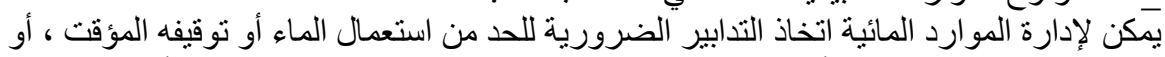

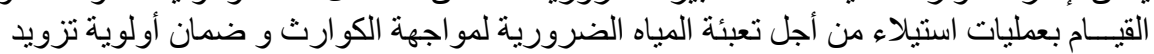


السكان و المواثــــي بالماء(32)، في غير هذه الحالات يمنع استغلال المياه الحموية لأغراض زر اعية ،

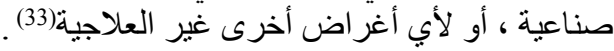

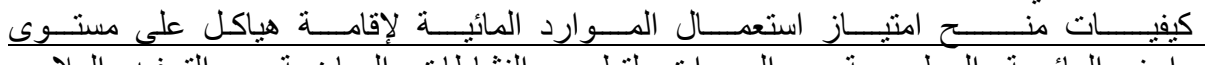

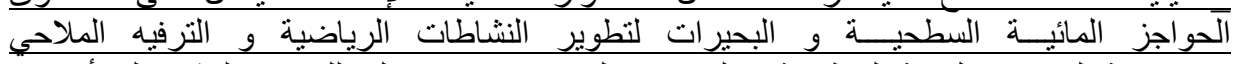

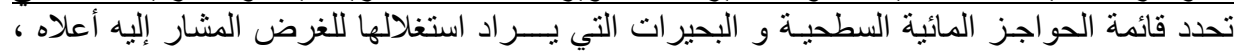

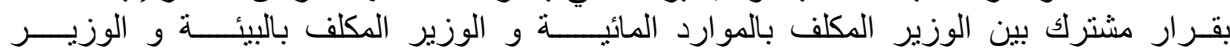

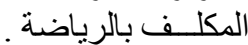

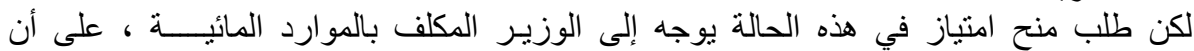

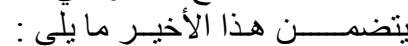
بالنسبـــة للأشخــاص الطبيعيين ، الاسم و اللقب و العنوان ، أما بالنسبة للأشخاص المعنويين اسم

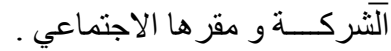
تعيين الحاجز المائي السطحي أو البحيـرة ، و كذا النشاطات الرياضيـة ، و الترفيه الملاحي المنصوص عليه.

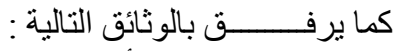

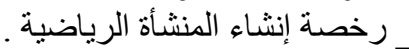

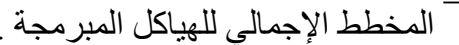

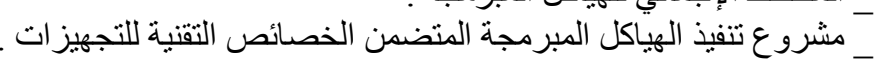

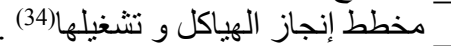

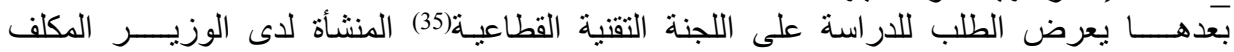

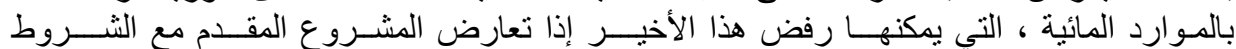

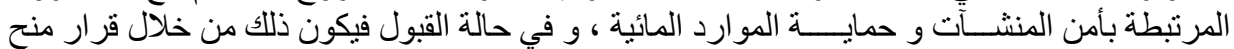

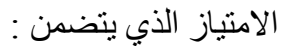

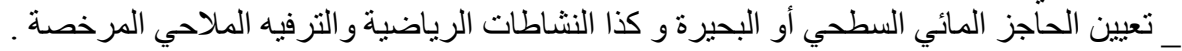

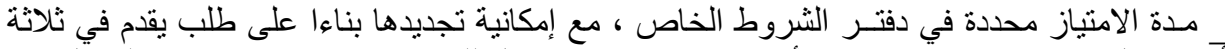

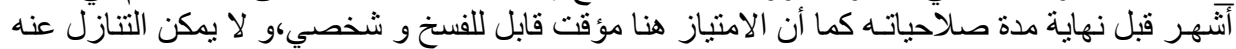

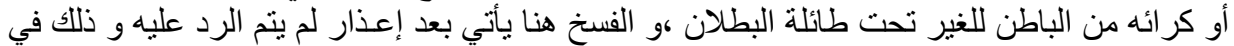

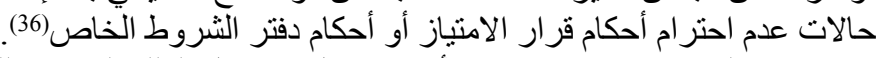

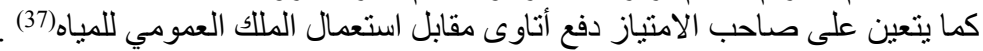

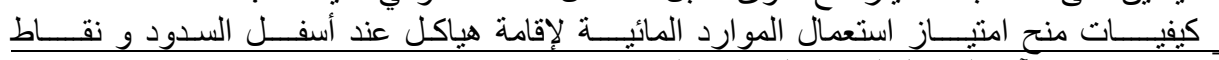

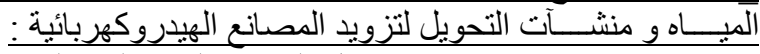

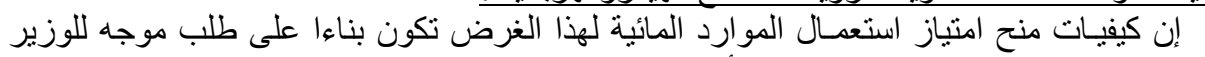

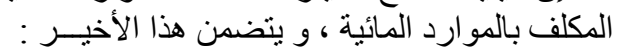

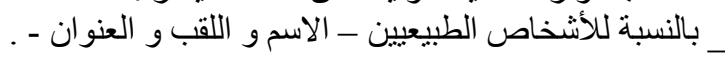


ب بالنسبة للأشخاص المعنويين - اسم الثركة و عنو ان مقر ها الاجتماعي - .

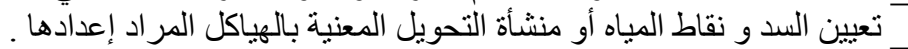

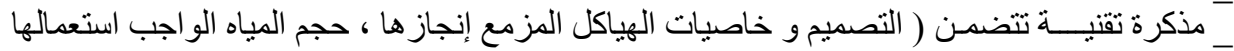

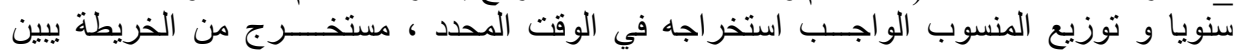

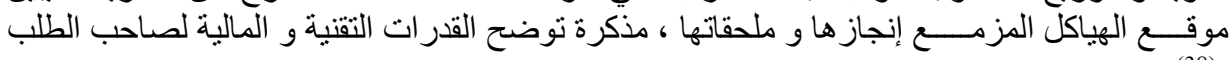
${ }^{(38)}($

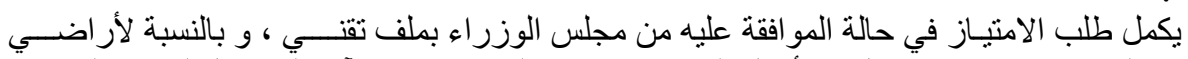

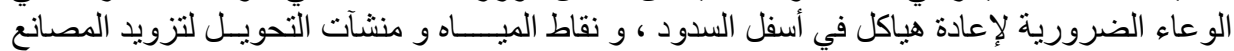

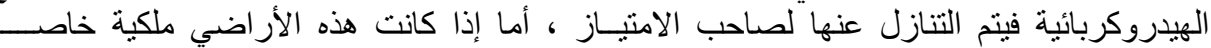

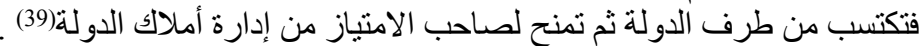

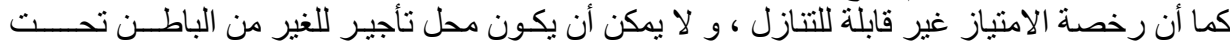

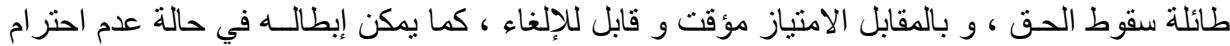

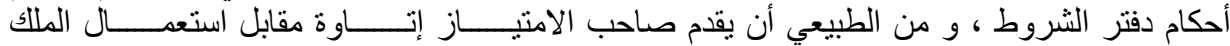

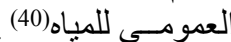

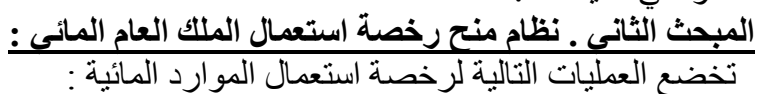

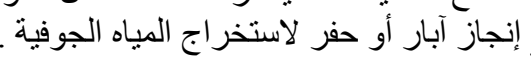

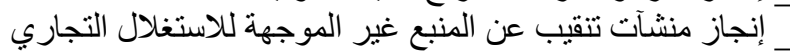

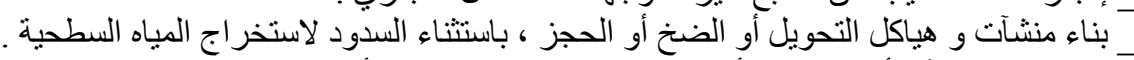

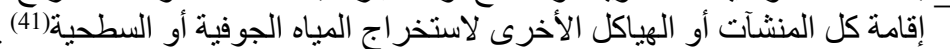

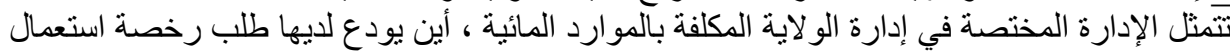

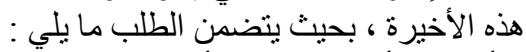

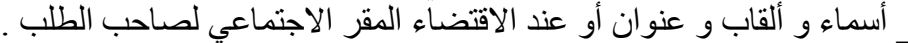
كـرة التبرير بعقد رسم لثغل الأرض أو الأراضي المخصصة لموقع منشآت أو هياكل استخر اج الماء من طَرف الطبيعة و الموقع الجلب . لمغر افي و مخطط وضعية منثأة أو هيكل استخر اج الماء بمفهوم أحكام المادة 75

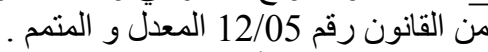

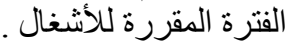

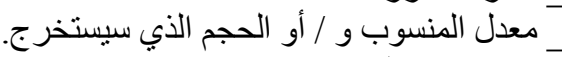

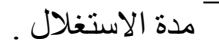

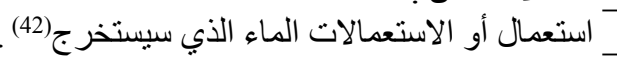
ـ كما يجب أن برفــق الطلب الوثائق التقنتية المطلوبة لإنجاز كل صنف منثــأ ، أو هيكل استعمال

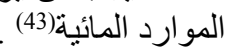


يخضع طلب رخصة استعمال الموارد المائية إلى تعليمة تقنية تعدها مصالح إدارة الولاية المكلفة

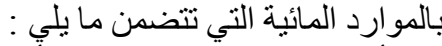

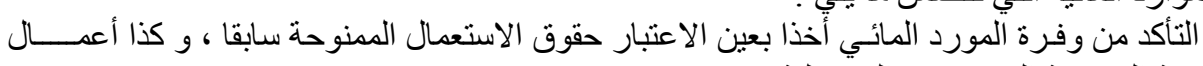

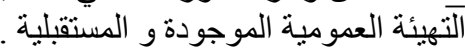

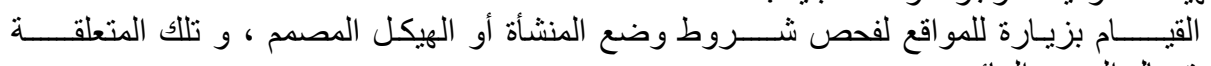
بآستعمال المورد المائي .

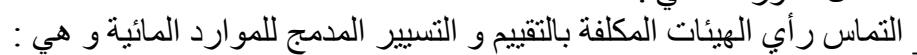

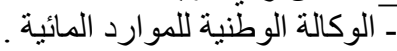

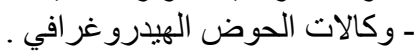

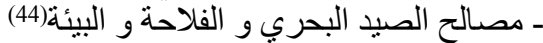

يمنح الوالي رخصة استعمال الموارد المائية بناءا على نتائج التعليمة التقنية ،على أن ييين في قراره ما

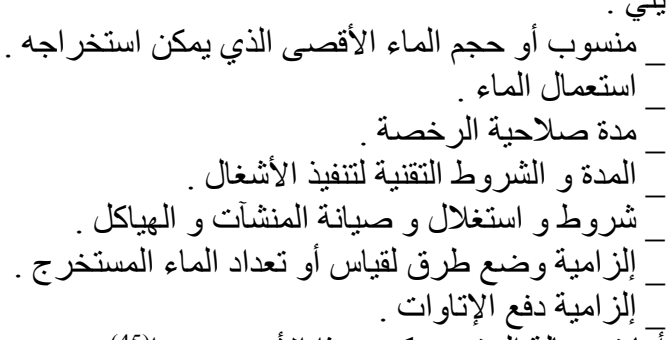

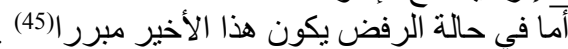

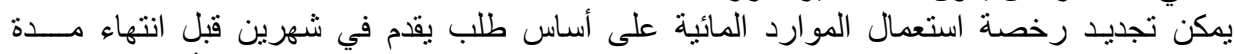

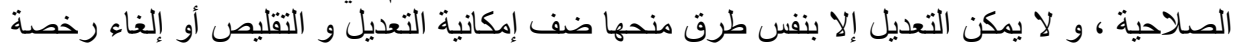
استخر اج الماء في الحالات ، و حسب الانب الكيفيات المنصوص طلائ عليها في المادة 86 و 87 من قانون المياه المعدل و المتمح .

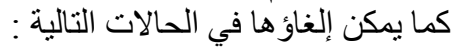

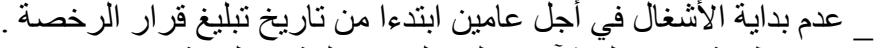

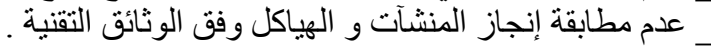

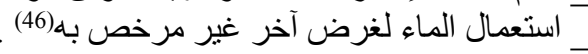

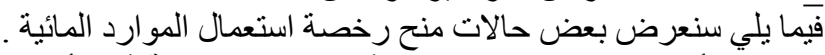

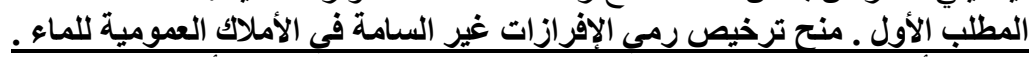

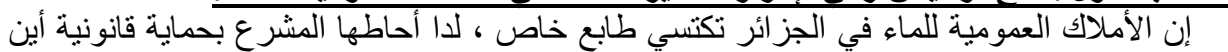

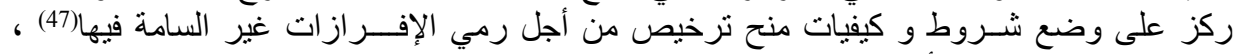

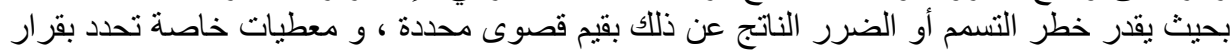


وزيـــر الموارد المائية ، مع الأخذ بعين الاعتبار ضعف الأمسلاك العمومية المائيـــة مقارنة بقيم

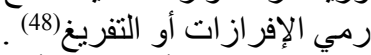

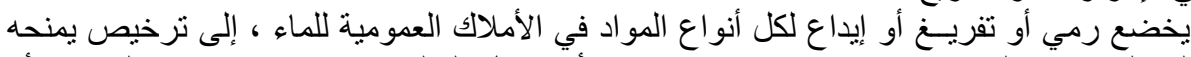

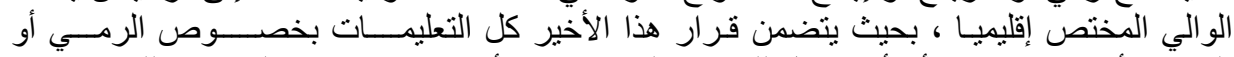

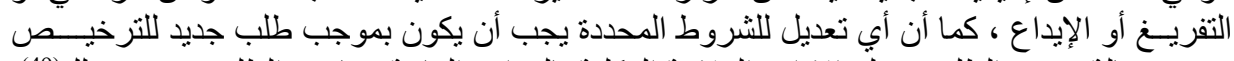

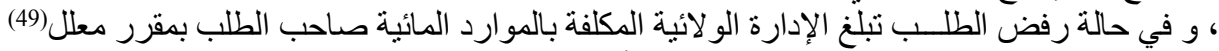

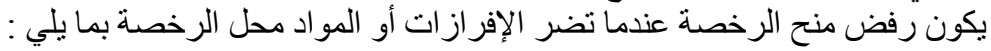

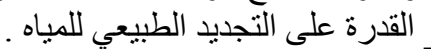
متطلبات استعمال المياه . -

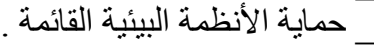
- السيلان العادي للمياه . -

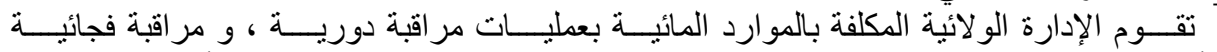

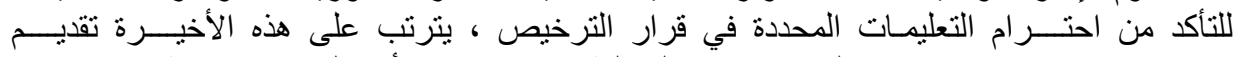

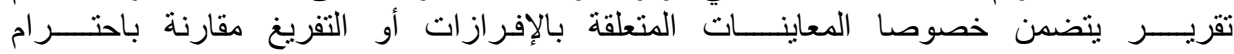

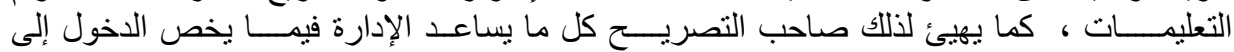

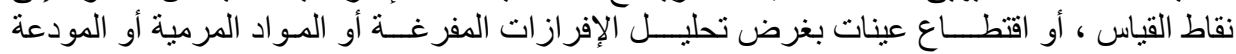

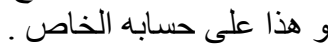

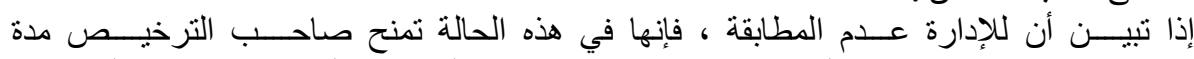

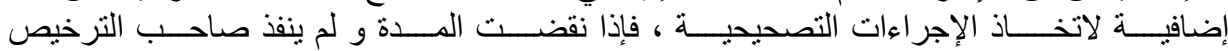
يعلن الو الي المختص إقليميا إلغاء الترخيص(51) .

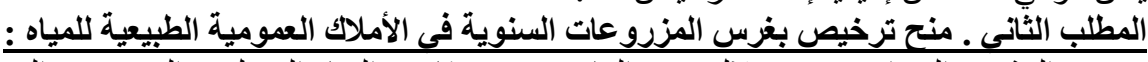

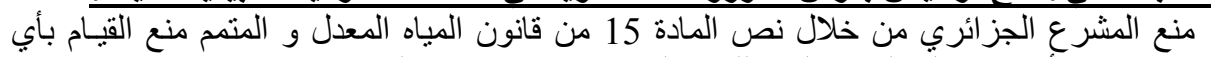

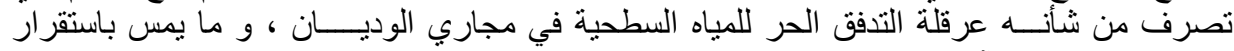

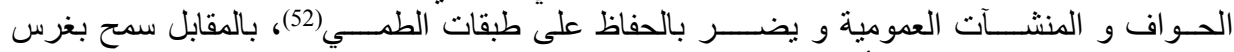

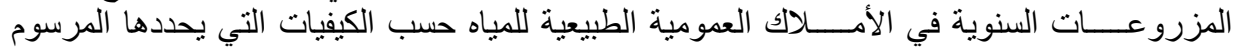

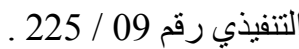
حيث يجب أن يتضمن قرار الو الي المختص إقليميا بالترخيص على وجه الإلز ام ما يلي :

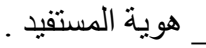
ـــــــع وقية مساحة القطعة أو القطع الأرضية المزمع استغلالها .

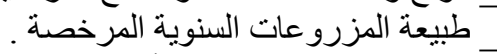
ــ شروط استغلال القطع من أجل الوقاية من تدهور الأملاك العمومية الطبيعية للمياه(53) . 
المطلب الثالـــث. منتح الترخيص بتفريغ المياه القذرة غير المنزلبـــة في الثبكة العموميــة للتطهيـر

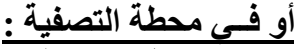

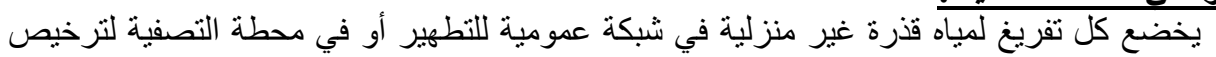

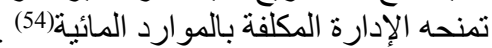

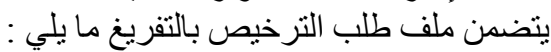

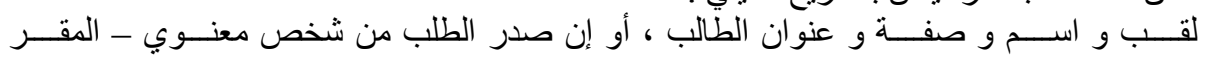

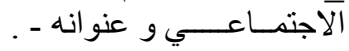

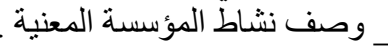

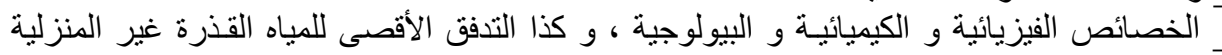
الو اجب تفريغها . التصني الخصائص التقنية للتوصيل بالثبكة العمومية للتطهير أو بمحطة التصفية . التهية عند الاقتضاء الوصف التقني لهياكل المعالجة الأولية التي تسمح باحتر ام شروط تفريغ المياه القفرة ،

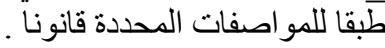

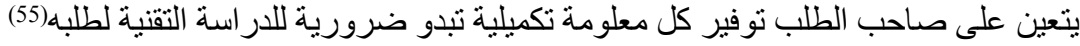

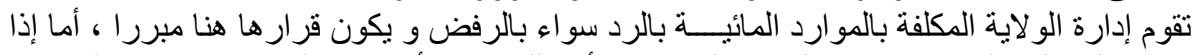

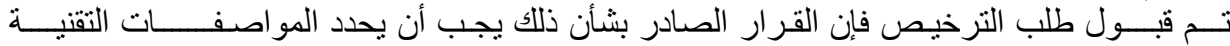

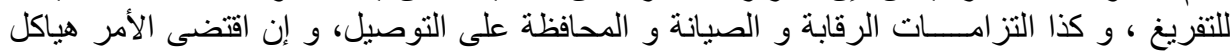
المعالجة الأولية . إذا أرد المعني بطلب الترخيص المقبول المبول التوسيع أو التحويل أو الإعادة إلى وضع سابق أو تغيير في

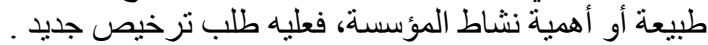

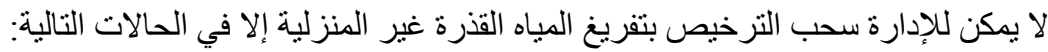

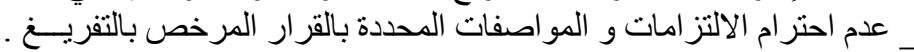

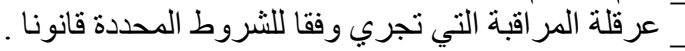

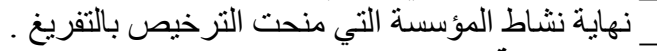

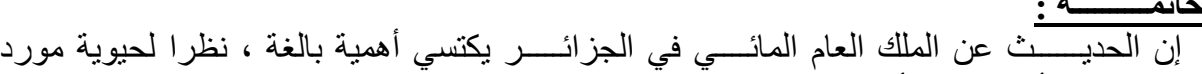

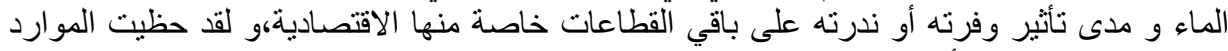

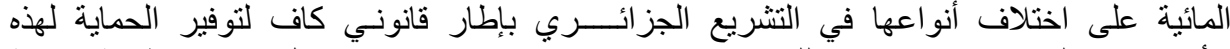

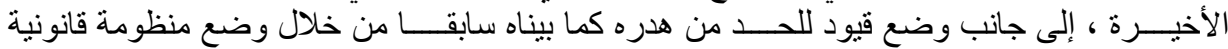

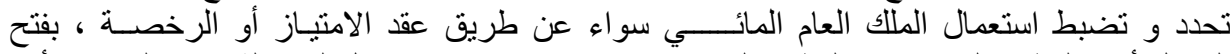

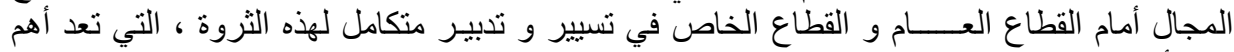

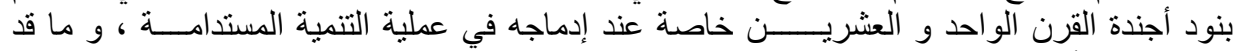

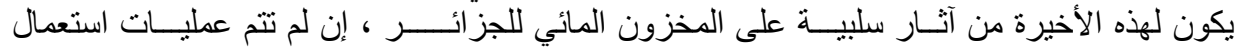


الملك العام المائي من خلال إدارة متكاملة و رشيدة .

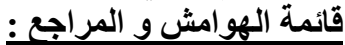

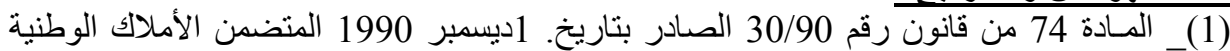

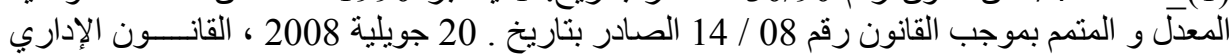

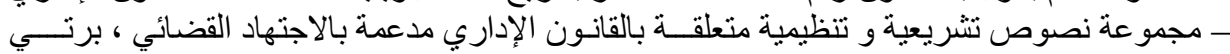

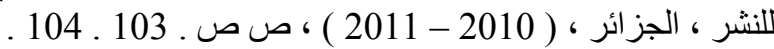

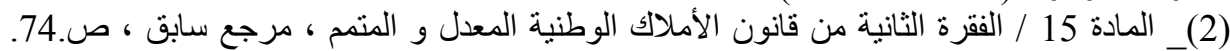

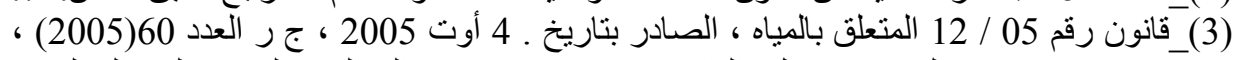

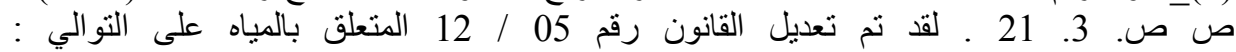

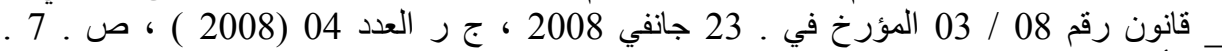

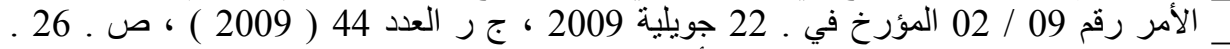

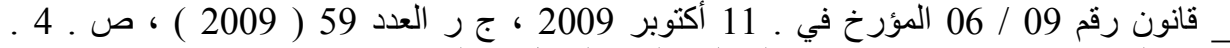

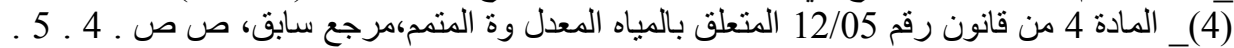

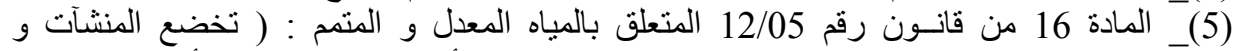

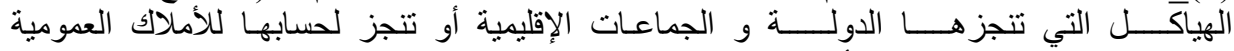

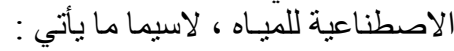

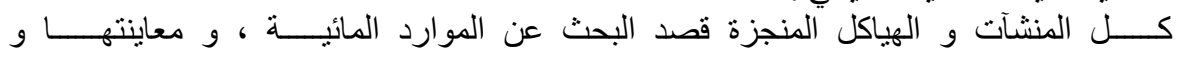

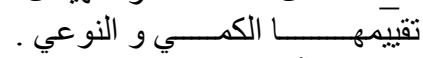

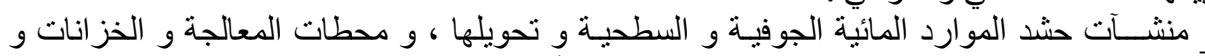

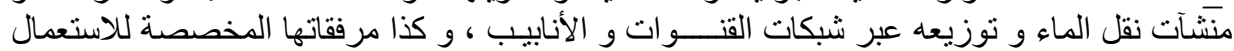

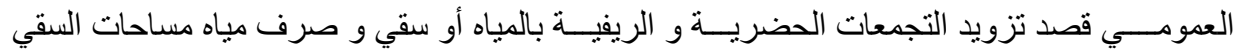

مجمعات المياه القذرة و مياه الأمطار و محطات التصفية، و كذا مرفقاتها المخصصة للاستعمال

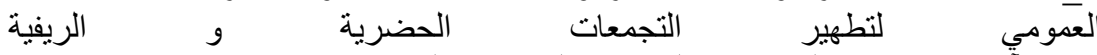

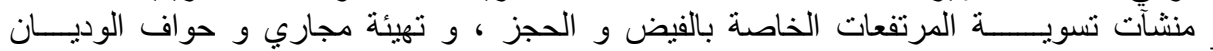

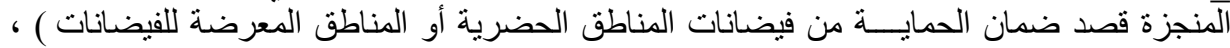

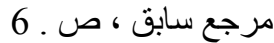

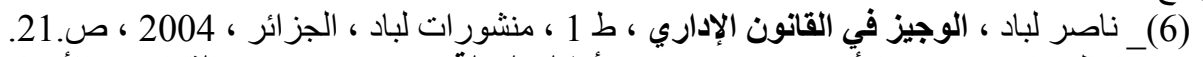

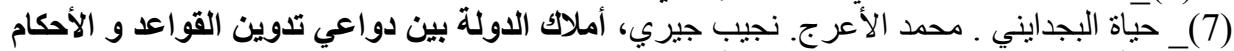

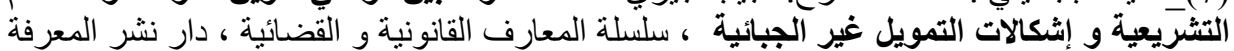

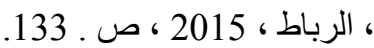
(8)- Jean-Luc Aubey, Le contrat - Droit des obligations - , $2^{\mathrm{m}}$ ed, Dalloz , Paris , 2000, p. 19 . 


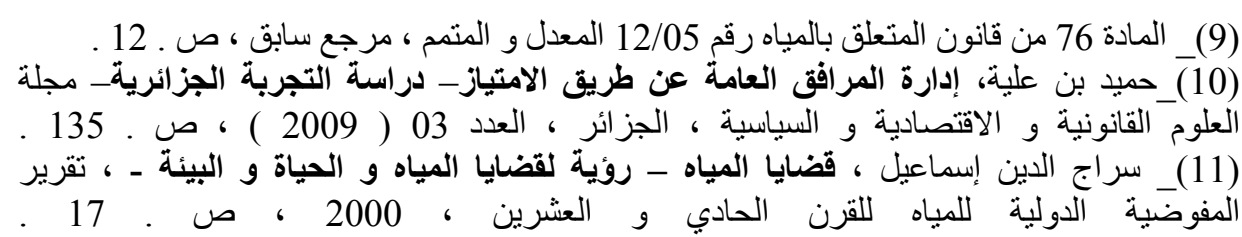

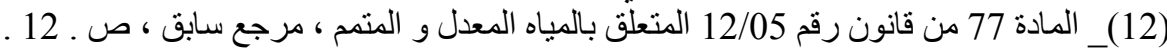

(13)- Article 4 de Décret n $10 / 318$ du . 21 décembre 2010 fixant les modalités d'octroi de la concession d'utilisation des ressources en eau dans les systèmes aquifères fossiles ou faiblement renouvelables, ainsi que le cahier des chargestype y afférent, $\mathrm{J} \mathrm{O} \mathrm{n}^{\circ} 77$ ( 2010 ), p . 7 .

Article 3 de Décret $n^{\circ} 10 / 318$ du . 21 décembre 2010 fixant les modalités d'octroi de la concession d'utilisation des ressources en eau dans les systèmes aquifères fossiles ou faiblement renouvelables, ainsi que le cahier des chargestype y afférent: ( La demande de concession d'utilisation des ressources en eau est adressée au wali territorialement compétent et doit contenir les éléments d'identification du demandeur notamment :

- pour les personnes physiques, les noms prénom(s) et adresse, et pour les personnes morales, la raison sociale et l'adresse du siège social ;

- la justification, par acte authentique, de l'occupation par le demandeur du ou des terrain(s) d'assiette d'implantation du (des) forage(s) projetés) ;

- le ou les usages de l'eau.

La demande doit être accompagnée d'un dossier technique comprenant les documents suivants :

-un extrait de carte à l'échelle 1/50.000ème ou 1/200.000ème indiquant la localisation du (des) forage(s) ;

- une note sur l'hydrogéologie de la zone d'implantation du (des) forage(s) indiquant la description des formations susceptibles d'être aquifères, les niveaux statiques, les débits et rabattements obtenus ainsi que les caractéristiques de la qualité de l'eau ;

- la coupe prévisionnelle du (des) forage(s) ;

- le programme de fonçage du (des) forage(s) indiquant ses différentes phases 
et opérations à réaliser ;

- le programme prévisionnel de l'équipement du(des) forage(s) en tubes pleins et crépines

- le programme de développement et des essais de pompage ).

(14)- Article 8 de Décret $n^{\circ} 10 / 318$, fixant les modalités d'octroi de la concession d'utilisation des ressources en eau dans les systèmes aquifères fossiles ou faiblement renouvelables, ainsi que le cahier des charges-type y afférent, op. cit , p.7.

(15)- Article 2 de Décret exécutif $n^{\circ} 10-25$ du 12 janvier 2010 fixant les modalités d'octroi de la concession pour l'établissement d'installations de prélèvement d'eaux souterraines ou superficielles, en vue d'assurer un approvisionnement autonome de zones ou unités industrielles , $\mathrm{J} \mathrm{O} \mathrm{n}^{\circ} 4$ ( 2010 ), p. 13 .

(16)- Articles de 5 a 9 de Décret exécutif n ${ }^{\circ} 10-25$ du 12 janvier 2010 fixant les modalités d'octroi de la concession pour l'établissement d'installations de prélèvement d'eaux souterraines ou superficielles, en vue d'assurer un approvisionnement autonome de zones ou unités industrielles, op.cit, p p . 13 . 14 .

(17)- Article 13 de Décret exécutif $n^{\circ} 10-25$ du 12 janvier 2010 fixant les modalités d'octroi de la concession pour l'établissement d'installations de prélèvement d'eaux souterraines ou superficielles, en vue d'assurer un approvisionnement autonome de zones ou unités industrielles, op.cit, p . 14 . (18)- Article 3 de Décret exécutif n ${ }^{\circ} 11-220$ du 12 juin 2011 fixant les modalités de la concession d'utilisation des ressources en eau pour l'établissement d'installations de dessalement d'eau de mer ou de déminéralisation d'eaux saumâtres pour cause d'utilité publique ou pour la satisfaction de besoins propres, $\mathrm{J} \mathrm{O} \mathrm{n}^{\circ} 34$ ( 2011), p . 7 . (19)- Article 5 de Décret exécutif n ${ }^{\circ} 11-220$,fixant les modalités de la concession d'utilisation des ressources en eau pour l'établissement d'installations de dessalement d'eau de mer ou de déminéralisation d'eaux saumâtres pour cause d'utilité publique ou pour la satisfaction de besoins propres, op . cit, p . 7 .

(20)- Article 4 de Décret exécutif n 11-220,fixant les modalités de la 
concession d'utilisation des ressources en eau pour l'établissement d'installations de dessalement d'eau de mer ou de déminéralisation d'eaux saumâtres pour cause d'utilité publique ou pour la satisfaction de besoins propres, op . cit, p . 7 .

(21)- Art 7 de Décret exécutif $n^{\circ} 11-220$ : ( Lorsque la demande fait l'objet d'accord, elle est complétée par un dossier technique comprenant les documents suivants :

. l'engagement écrit du concessionnaire du service public d'alimentation en eau potable à utiliser les volumes d'eau produite dans un but d'utilité publique ;

. L'étude d'impact prévue par la législation et la réglementation en vigueur ; . le projet d'exécution des installations projetées ;

. le planning de réalisation et de mise en service des installations ), op . cit , p . 8 .

(22)- Articles de 8 a 14 de Décret exécutif n 11-220, op . cit, p . 8 .

(23)- L'eaux usée épurée destinée à l'irrigation est toute eau usée dont la qualité, après un traitement approprié dans une station d'épuration

(24)- Articles de 3 a 5 de Décret exécutif $n^{\circ}$ 07-149 du 20 mai 2007 fixant les modalités de concession d'utilisation des eaux usées épurées à des fins d'irrigation ainsi que le cahier des charges-type y afférent, $\mathrm{J} \mathrm{O} \mathrm{n}^{\circ} 35$ ( 2007 ), p. 8 .

(25)- Articles - 7, 10, 11, 12 - de Décret exécutif $\mathrm{n}^{\circ}$ 07-149, fixant les modalités de concession d'utilisation des eaux usées épurées à des fins d'irrigation ainsi que le cahier des charges-type y afférent, op .cit , p . 9 .
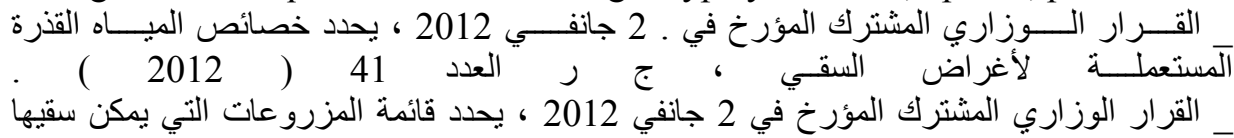

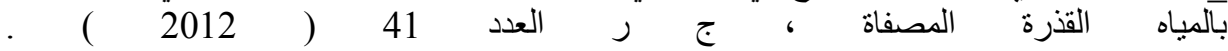

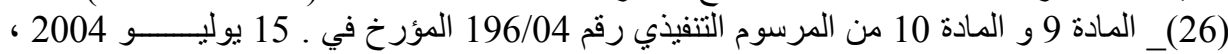

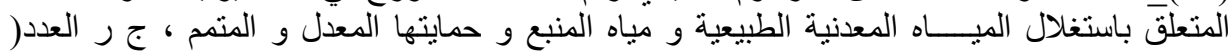

(27)- Article 4 de Décret exécutif n 12-187 du 25 avril 2012 modifiant et complétant le décret exécutif $\mathrm{n}^{\circ}$ 04-196 relatif à l'exploitation et à la protection des eaux minérales naturelles et des eaux de source, $\mathrm{J} \mathrm{O} \mathrm{n}^{\circ} 25$ ( 
$2012)$, p. 6.

Aussi : L'Arrêté du 18 janvier 2006 fixant la liste des laboratoires effectuant les analyses de la qualité des eaux minérales naturelles et des eaux de source, $\mathrm{J}$ $\mathrm{On}^{\circ} 12$ (2006), p p . 29.30.

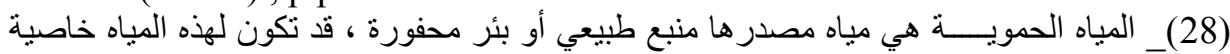

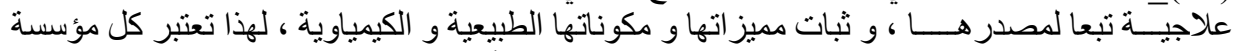

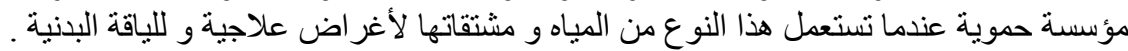

(29)- Articles - 15-16-23-24 - Décret exécutif n ${ }^{\circ}$ 07-69 du correspondant au 19 février 2007 fixant les conditions et les modalités d'octroi de la concession d'utilisation et d'exploitation des eaux thermales, $\mathrm{J} \mathrm{O} \mathrm{n}^{\circ} 13$ ( 2007 ), p p. 8.9 .

(30)- Articles 25 et 28 de Décret exécutif n 07-69, fixant les conditions et les modalités d'octroi de la concession d'utilisation et d'exploitation des eaux thermales, op . cit, p. 9 .

(31)- Articles 33-37 et 57 de Décret exécutif n 07-69, fixant les conditions et les modalités d'octroi de la concession d'utilisation et d'exploitation des eaux thermales, op . cit, pp . 10.12.

$$
\text { المادة } 91 \text { من قانون رقم 12/05 المتعلق بالمياه ، مرجع سابق ، ص ـ } 13 \text { ـ } 12 \text {. }
$$

(33)- Articles 21 de Décret exécutif n 07-69, fixant les conditions et les modalités d.octroi de la concession d'utilisation et d'exploitation des eaux thermales, op . cit, p. 8 .

- Ce décret est modifié par le Décret exécutif nº 12-205 du 6 mai 2012 , J O n ${ }^{\circ}$ 29 ( 2012 ), pp . 5.6 .

(34)- Articles 2 . 4 . 5 de Décret exécutif n 11-340 du 26 septembre 2011 fixant les

modalités de concession d'utilisation des ressources en eau pour l'établissement d'installations au niveau des retenues d'eau superficielle et des lacs en vue d'y développer des activités de sports et loisirs nautiques , J O n ${ }^{\circ}$ 54 ( 2011$),$ p. 4 .

(35)- Art. 7 de décret exécutif $n^{\circ}$ 11/340 : ( La commission prévue à l'article 6 ci-dessus est présidée par le représentant du ministre chargé des ressources en eau et comprend :

. le représentant du ministre chargé de l'environnement ; 
. le représentant du ministre chargé des sports ;

. le représentant du ministre chargé de la pêche ;

. le représentant du ministre chargé du tourisme;

. le représentant de la gendarmerie nationale ;

. le représentant de la direction générale de la protection civile;

. le directeur général des forêts ou son représentant ;

. le directeur général de l'agence nationale des barrages et transferts ou son représentant.

Le secrétariat de la commission est assuré par les services du ministère des ressources en eau ).

(36)- Articles de 10 a 14 de Décret exécutif n 11-340 du 26 septembre 2011

fixant les

modalités de concession d'utilisation des ressources en eau pour

l'établissement d'installations au niveau des retenues d'eau superficielle et des

lacs en vue d'y développer des activités de sports et loisirs nautiques, op .cit , p. 5 .

(37)- Art 15 de Décret exécutif n 11-340 du 26 septembre 2011 fixant les modalités de concession d'utilisation des ressources en eau pour

l'établissement d'installations au niveau des retenues d'eau superficielle et des lacs en vue d'y développer des activités de sports et loisirs nautiques, op .cit , p. 5 .

(38)- Art 5 de Décret exécutif n ${ }^{\circ} 11-341$ du 26 septembre 2011 fixant les modalités de concession d'utilisation des ressources en eau pour l'établissement d'installations au pied des barrages, plans d'eau et ouvrages de dérivation en vue d'alimenter des usines hydroélectriques, J0 , n 54 ( 2011), p .7 .

(39)- Art 8 et 12 de Décret exécutif $n^{\circ}$ 11-341,fixant les modalités de concession d'utilisation des ressources en eau pour l'établissement d'installations au pied des barrages, plans d'eau et ouvrages de dérivation en vue d'alimenter des usines hydroélectriques, op . cit, pp . 7 .8 .

(40)- Articles de 13 a 15 Décret exécutif $n^{\circ} 11-341$, fixant les modalités de concession d'utilisation des ressources en eau pour l'établissement d'installations au pied des barrages, plans d'eau et ouvrages de dérivation en 
vue d'alimenter des usines hydroélectriques, op . cit, p . 8 .

(41)_ المادة 71 و المادة 74 من قانون رقم 12/05 المتعلق بالمياه المعدل و المتمم ، مرجع سابق ،

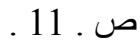

المادة 75 من قانون رقم 12/05 المتعلق بالمياه المعدل و المتمم ، مرجع سابق ، ص ص ـ 11

. 12 .

(43)- Art 2 de Décret exécutif $\mathrm{n}^{\circ}$ 08-148 du 21 mai 2008 fixant les modalités

d'octroi de l'autorisation d'utilisation des ressources en eau, JO , n 26 ( 2008

), p. 7 .

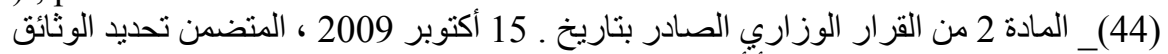

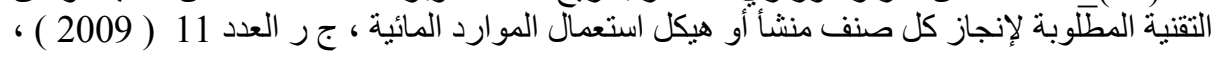

. 12 (20)

(45)- Art 3 de Décret exécutif ${ }^{\circ}$ 08-148, fixant les modalités d'octroi de

l'autorisation d'utilisation des ressources en eau, op . cit, p . 7 .

(46)- Arts 4 et 5 et 6 de Décret exécutif $n^{\circ} 08-148$, fixant les modalités

d'octroi de l'autorisation d'utilisation des ressources en eau, op . cit, p . 7 . 8 .

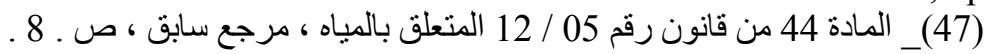

(48)- Art 2 de Décret exécutif n 10-88 du 10 mars 2010 fixant les conditions et les modalités d'octroi d'autorisation de rejets d'effluents non toxiques dans le domaine public hydraulique, $\mathrm{JO}, \mathrm{n}^{\circ} 17$ ( 2010 ), p . 5 .

(49)- Articles 3-4-5 de Décret exécutif n ${ }^{\circ} 10-88$ du 10 mars 2010 fixant les conditions et les modalités d'octroi d'autorisation de rejets d'effluents non toxiques dans le domaine public hydraulique, op . cit, p . 5 .

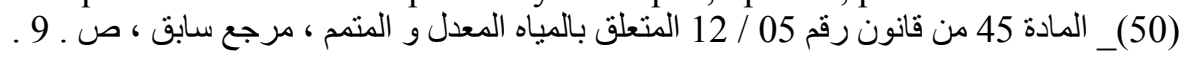

(51)- Articles de 6 a 11 de Décret exécutif n 10-88 du 10 mars 2010 fixant les conditions et les modalités d'octroi d'autorisation de rejets d'effluents non toxiques dans le domaine public hydraulique, op . cit , p . 5 .

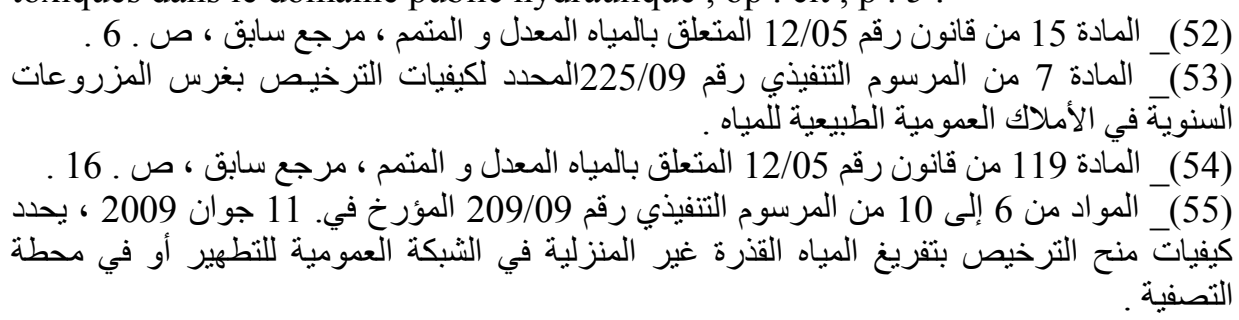

